\title{
Energy efficient water damage restoration by insulated wall drying panels
}

\author{
Hartwig Künzel $^{\text {a*}}$, Andreas Zegowitz ${ }^{\mathrm{b}}$ \\ aFraunhofer IBP, Holzkirchen, Germany \\ bFraunhofer IBP, Stuttgart, Germany
}

\begin{abstract}
Water damage due to leaking water pipes or bulk water entry during torrential rain events is a worldwide problem. To avoid building degradation or mould formation, water removal should be fast and effective, usually requiring special drying equipment. Since the conventional restoration methods, such as infrared panels or adsorption and condensation dryers, are rather energy intensive, a novel drying device has been developed and tested. This device consists of a panel with heating wires in close contact with the wet wall covered by a diffusion-open insulation and a vapour permeable backside. Moisture evaporated from the heated wall penetrates the insulation layer by diffusion while the heat loss into the room is rather small thanks to the insulation layer. Compared to conventional restoration equipment, energy savings reach up to $80 \%$ at the same drying rate.
\end{abstract}

Peer-review under the responsibility of the organizing committee of the ICMB21.

Keywords: Water damage restoration; energy efficient drying; wall drying panel; vapour permeable insulation;

\section{Introduction/Background}

Restoring water damage requires time, effort and energy because special drying devices are often necessary. Drying of wet walls is either done by heating the wall, e.g. by infrared panels, or by lowering the ambient humidity with adsorption or condensation drying systems. Both methods show high power consumptions because they not only heat or dehumidify the wet wall sections but also the ambient air [1]. Therefore, a drying device that is directly attached to the wet wall area has been developed and tested. The basic principle of this device and its performance in comparison to conventional drying systems is described in [2] and summarized below.

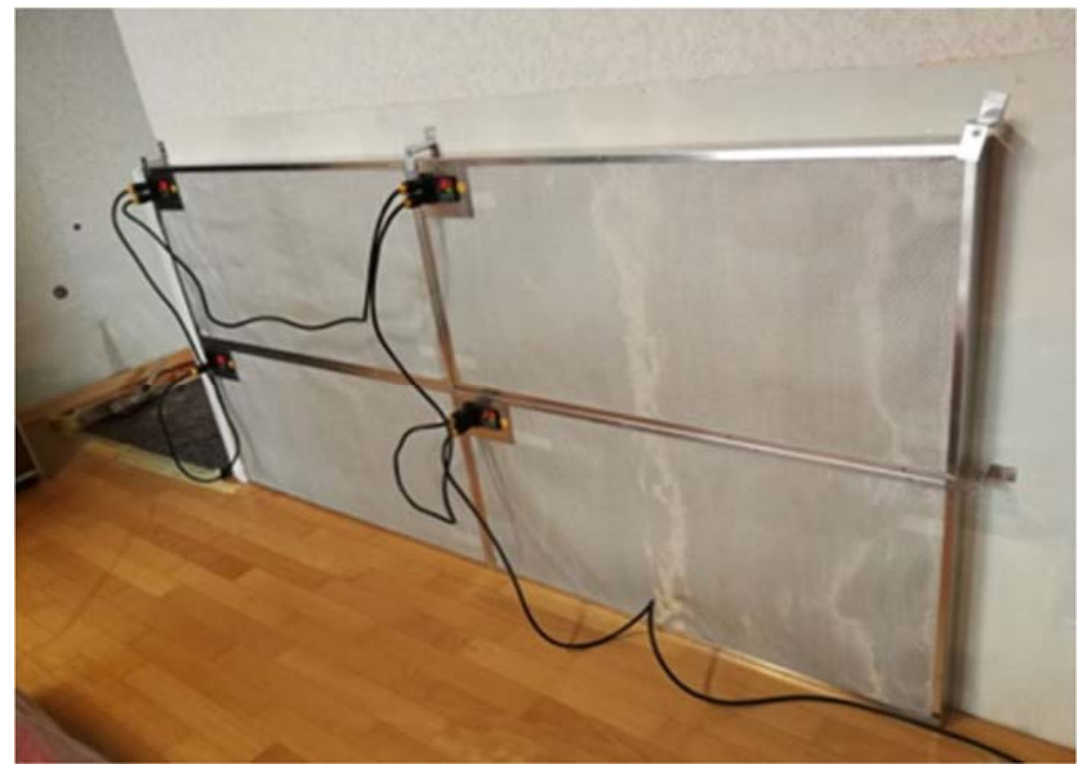

(a)

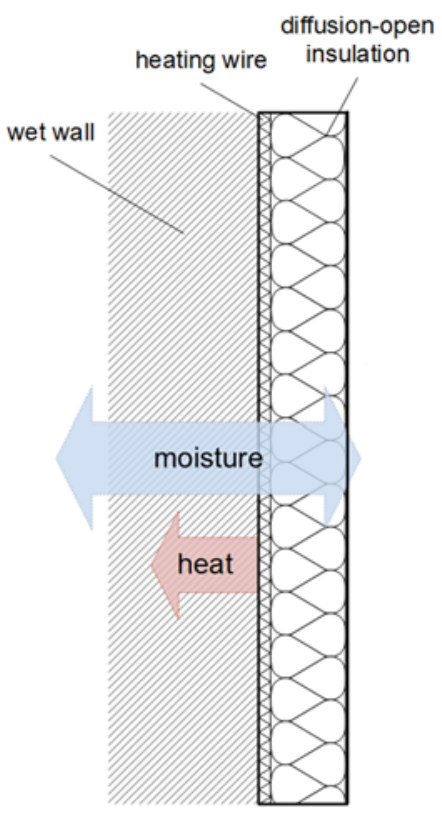

(b)

Figure 1 (a) New wall drying panel attached to a wet wall; (b) working principle

\footnotetext{
* Corresponding author.+498024643245 hartwig.kuenzel@ibp.fraunhofer.de
} 


\section{Working principle and performance of the new wall drying panel}

The drying panel and its working principle are shown in Fig. 1. It simply consists of a vapour permeable envelope material on both sides with temperature controlled heating wires under the panel's surface attached to the wall. The wires are covered by a permeable insulation layer (e.g. mineral fibre board) that keeps the heat in the wall and lets the moisture penetrate via diffusion towards the ambient air. Thus only the latent heat of the water in the wall escapes into the ambient air while the sensible heat loss is considerably reduced by the insulation.

To compare the performance of the new wall drying panel with conventional systems (infrared drying panels and adsorption dehumidifiers) [3], two identical brick masonry walls were built-up in a climate chamber set to $20^{\circ} \mathrm{C}$ and $50 \% \mathrm{RH}$. These $1 \mathrm{~m}^{2}$ large wall sections are comparable to internal partitions, where most of the water pipe damages occur. To reproduce an artificial water damage the walls were exposed to a $70 \mathrm{~mm}$ high water level over several days. Then the water got drained off and the walls were dried with different systems. During the drying process surface temperatures as well as moisture contents at 3 levels and 4 depth of the wall samples were continuously monitored. Also the energy consumption of the different drying systems and the total weight of the wall samples have been recorded and evaluated.

The overall results of several such tests are shown in Fig. 2. The drying process of the wall sections determined by weighing (a) with the infrared heating panel is very similar to that with the new insulated drying panel (both heat the wall surface to $50^{\circ} \mathrm{C}$ ) while the adsorption dehumidifier is much less effective. The energy consumption necessary to reach the target value (water content of the wall samples before the simulated water damage) in (b) demonstrates a huge difference in energy efficiency, proving the large savings possible if the heat dissipation to the ambient air is well contained during the restoration process.

(a)

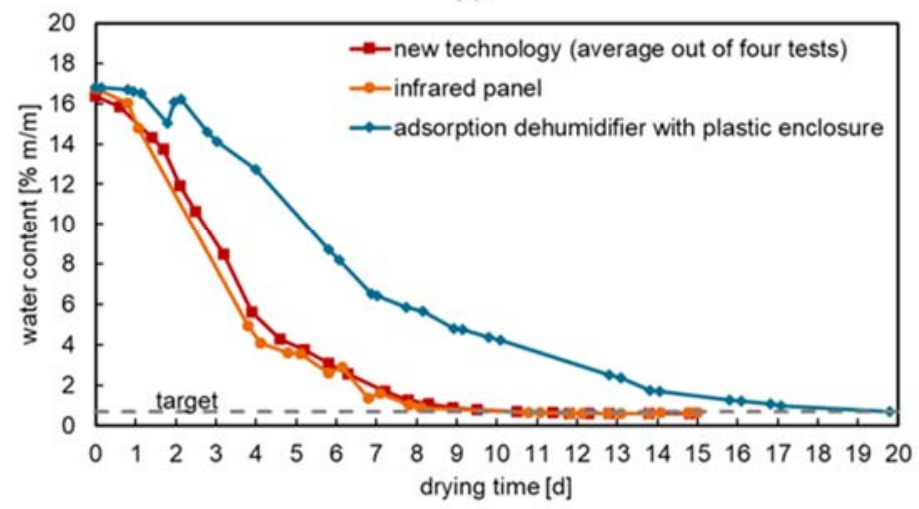

(b)

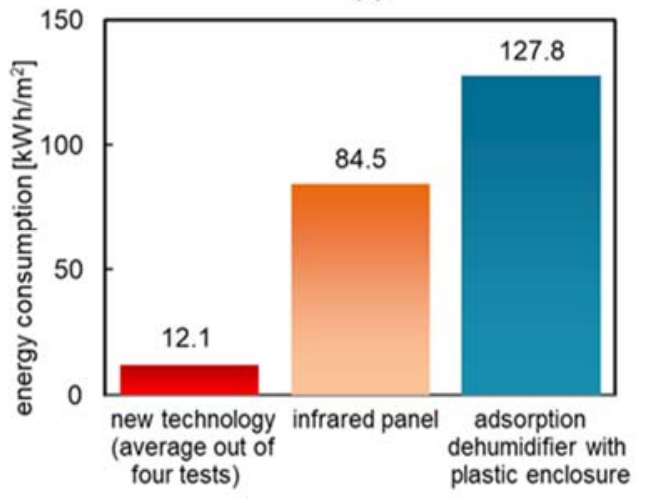

Figure 2. (a) Drying course of wet wall samples; (b) Energy consumed to achieve the dry state again.

\section{Conclusions}

Laboratory tests and a first real life application case have clearly show, that drying of wet walls using the new insulated drying panel, consumes much less energy than conventional systems. The energy savings are up to $80 \%$ compared to infrared panels and up to $90 \%$ compared to adsorption dehumidifiers. This demonstrates the potential to save electricity by keeping heat and/or dry air strictly at the location of the wet building component and avoid dissipation of heat to the ambient air or neighboring dry component sections. In contrast to partition walls external walls are mostly thicker and often insulated and thus more difficult to dry. In this case higher temperatures will help to a certain extend as further test have shown. Since temperatures above $60^{\circ} \mathrm{C}$ pose the risk of burn injuries to people infrared panels cannot be used here anymore. With the insulated wall drying panel higher wall surface temperatures can be realized as long as the panel is safely attached to the wall to avoid direct access hot surfaces.

The paradigm of heat being more effective than dry air is not only valid for walls but also for other building components affected by water leakage such as ceilings and floors (e.g. under screed drying) or other interstitial spaces. It appears to be worthwhile to improve current restoration practices and systems to reduce the electricity consumption, aiming at getting close to the amount of energy required to evaporate the access water, without unnecessarily heating or dehumidifying the environment.

Insurance companies in Germany (they have to pay the electricity bill for all restoration measures) have recognized this savings potential and are now pushing restoration companies to apply more energy efficient drying technologies. This will certainly help to force the rather conservative restoration sector to become more innovative in the future.

\section{References}

[1] Fraunhofer Institute for Building Physics. (2017). Test report: Untersuchung des Trocknungsverhaltens von Fußbodenaufbauten und angrenzenden Wänden sowie von Deckenaufbauten mit natürlicher und mechanischer Trocknung nach einem Wasserschaden Stock profile and condition. Stuttgart.

[2] Pfister, H. (2019). Master thesis: Comparison of conventional technics for masonry drying with a diffusion-open, technical drying system. University Stuttgart.

[3] WTA Merkblatt 6-15. (2013). Technische Trocknung durchfeuchteter Bauteile Teil 1 - Grundlagen. München 